ORIGINAL PROF-2078

\title{
PSYCHIATRIC DISORDERS;
}

Pattern and trends of patients attending out patent department at Govt. Sarhad Hospital for psychiatric illnesses, Peshawar.

\author{
Dr. Raheelah Amin, Dr. Rubina Gul, Dr. M. Akbar Khan, Dr. M. Tariq, Dr. Shafiqullah, Dr. Amina Mehrab
}

ABSTRACT ... Objectives: The study was conducted to examine the pattern/trend of psychiatric disorders in a hospital based setting. Settings \& Period: Conducted at Govt. Sarhad Hospital for Psychiatric Diseases, Peshawar in March-April, 2010. Study Design: Simple Observational. Methods: A Retrospective record review was done to determine the disease pattern for patients examined in the OPD(out patient deptt.). All the patients who attended OPD in year 2010 and 2004 were included.The diseases were coded and classified according to ICD- 9 \& 10. Comparison \& Statistical analysis of both years was done. Results: The findings of the study suggested that disease pattern seen at hospital, represents mental diseases prevalent in Distt. Peshawar. It showed the predominance of schizophrenic group \& neurotic (31-35\%), stress related disorders (30-31\%) group over other diseases. Next were the mode effective disorders (12$16 \%$ ) and episodal \& paroxysmal disorders group (16-17\%). Drug dependence and mental retardation showed low percentage of $2 \%$. Rest of diseases also showed low percentage. Although similar patterns were observed for both years but there were statistically significant difference between the two years. Conclusions: Hospital utilization pattern is a useful guide to the prevalence of mental diseases in general community. The chronic illnesses consisted of major burden of disease. Major groups were Schizophrenic \& Neurotic, and Stress related disorders group. Pattern of psychiatric illness have not changed much from 2004 to 2010 . Although the hospital is catering a large number of patients, yet there is a dire need of organizing mental health services at community level to reach undiagnosed patients.

Key words: Mental Health, Mental Disorders, Mental Health Services, Mental Health Services/Trends/Utilization/Diagnosis, Psychiatric Illnesses.

\section{Article Citation}

$\checkmark \quad$ Amin R, Gul R, Khan MA, Tariq M, Shafiqullah, Mehrab A. Study of the pattern and trends of psychiatric disorders among patients attending out patent department at Govt. Sarhad Hospital for psychiatric illnesses, Peshawar. Professional Med J Feb 2013;20(1):126-131.

\section{INTRODUCTION}

There is no health without mental health. WHO statistics shows that mental disorders are major contributors to illness and premature death, and are responsible for 13 percent of the global disease burden. With the global economic downturn - and associated austerity measures, the risks for mental illhealth are rising around the globe. By 2020, they will account for nearly $15 \%$ of disability-adjusted life-years lost to illness. The burden of mental health disorder is maximal in young adults, the most productive section of the population ${ }^{1}$.

Economic cost of mental illness not only comprises of hospital services and medication but utilization of all resources of household of diseased persons in term of money, time and productive capacity.

It is important to identify vulnerable groups; the burden of mental disorders is not uniformly distributed in all sector of society. Those people living in stern conditions with poor resources face mental problems more.

By definition, mental health is a state of well-being in which every individual realizes his or her own potential, can cope with the normal stresses of life, can work productively and fruitfully, and is able to make a contribution to her or his community. It is also the absence of disability caused by a behavioral or psychological syndrome or pattern².

Many developing countries are still lagging behind in mental health services. In Pakistan mental health diseases are also not properly recognized. There is a vast practice of consulting faith healers in believing that it is some kind of possession by spirits. The treatment given is usually amulets, spiritually treated 
water, burning incense (dhooni), or reciting incantations.

The overall picture of mental ill health in 2004 in Pakistan shows prevalence of $6 \%$ depression, $1.5 \%$ for schizophrenia, 1-2\% of epilepsy and 1\% of Alzheimer's disease in general population. The prevalence of depression is highest followed by schizophrenia and substance abuse. Poverty, unemployment, political instability, violence and other social evils have influenced in rise of mental ill health problems. Various studies have shown that only $5 \%$ to $40 \%$ of people have access to mental health services. Problem of drug addiction is on rise ${ }^{3}$.

Since birth of Pakistan, lunacy act of 1912 was enacted. With more emphasis by WHO on mental health for its member countries and effort of Pakistani government new mental health legislation came into force on 20th, 2001.

However, Situation in Pakistan is bleak, as there is a dire need of changing whole mental health care delivery system. The emphasis should be put more on primary level rather then tertiary level, from curative to preventive one. A mental policy will be only effective if we implement it at all levels with earnest efforts ${ }^{5,6}$.

The study was conducted with the main objective of describing the pattern of diagnosis of the patients at psychiatric illness in hospital Peshawar, and the trends of the psychiatric disorders from 2004 to 2010.

\section{METHODOLOGY}

\section{Study Design}

Simple Cross sectional. Retrospective record review was done.

\section{Time \& Place}

Data collection was done in March-April 2011.

\section{Sample Size}

All the patients attending OPD service in whole year of $2004 \& 2010$ were included.

\section{METHOD}

Retrospective record review was done for year 2004 \& 2010 from govt. psychiatric illness hospital. Records were retrieved from hospital record room with the permission of authorities and examined in detail. It consisted of OPD patients records. A gap of five year was chosen for comparison i.e. year 2010 was compared with year 2004, who had paid visit to hospital during $2004 \& 2010$.

\section{Statistical Analysis}

Data available was in the form of individual diagnosis, it was properly coded with the help of a psychiatrist according to the latest international classification of diseases (ICD-9) \& (ICD-10). Data entry and univariate analysis was done using Microsoft Excel.

$P$ value was calculated using " $z$ test for two sample proportion" for comparisons of different diseases in two years.

Ethical considerations: As study was based on retrospective data collection, no informed consents were required. However, permission was taken from the hospital administration.

\section{RESULTS}

During the year 2004, a total of 46278 patients were seen by the hospital out patient deptt. i.e. about 140 patient/day approx. We observed the retrospective records. During the year 2010, a total of 53315 patients visited the hospital.

An overall pattern of diseases were observed in table I:

In 2004, there was predominance of Schizophrenia 16188(35\%) and Neurotic stress related disorders $14288(30.87 \%)$ over other diseases, then come the 
Episodal \& paroxysmal disorders $7408(16 \%)$ and then Mood effective disorders 5826 (12.59\%). Drug dependence showed a relatively low percentage i.e. $1111(2.4 \%)$. Similarly, mental retardation also showed low percentage i.e. 744(1.6\%).

In 2010, There was predominance of Schizophrenia 16818(31.55\%) and Neurotic stress related disorders $16880(31.66 \%)$ then Mood effective disorders $8626(16.18 \%)$ and then drug dependance was 296(0.56\%) and Mental Retardation was 900 (1.69\%).

In the figures $1 \& 2$, pattern of diseases is shown according to year 2004 and 2010, which is showing little variation in overall pattern. However, there was statistically significant difference between 2004 \& 2010 patterns of diseases with $p$ value $<0.05$, only the proportion of mental retardation was same in both samples with $p>0.05$. (as shown in Table I).

\section{DISCUSSION}

In our study, data was collected for two different years to assess the consistency in pattern of diseases. It was found that in both years almost similar frequency of patients visited the hospital.

WHO data from different countries shows that depression is the most common mental disease in societies $^{8}$. It is the leading cause of disability worldwide, while Schizophrenic group shows relatively low percentage of incidence, but high prevalence due to chronicity ${ }^{9}$. It has also been found that depression is relatively more common in developed countries with cold climate, while anxiety and neurosis are more common in under developed countries $^{10}$.

Data from mental hospital describes almost similar pattern. Schizophrenia showed the highest percentage followed by neurotic stress related group

\begin{tabular}{|l|l|c|c|c|}
\hline & \multicolumn{1}{|c|}{ Disease } & Year 2004 & Year 2010 & P-value \\
\hline F00-09 & Acute delirium & $150(0.32 \%)$ & $130(0.24 \%)$ & 0.018 \\
\hline F10-19 & Drug dependence & $1111(2.4 \%)$ & $296(0.56 \%)$ & 0.000 \\
\hline F20-29 & Schizophrenia, schizotypal ad delusional disorders & $16188(35 \%)$ & $16818(31.55 \%)$ & 0.000 \\
\hline F31-39 & Mood effective disorders & $5826(12.59 \%)$ & $8626(16.18 \%)$ & 0.000 \\
\hline F41-48 & Neurotic, stress related \& somatoform disorders & $14288(30.87 \%)$ & $16880(31.66 \%)$ & 0.008 \\
\hline F66 & Psychosexual disorders & $50(0.11 \%)$ & $15(0.028 \%)$ & 0.001 \\
\hline F70-79 & Mental retardation & $744(1.6 \%)$ & $900(1.69 \%)$ & 0.320 \\
\hline F90 & Attention deficient hyperkinetic disorder & $225(0.49 \%)$ & $144(0.27 \%)$ & 0.000 \\
\hline G20-26 & Extra pyramidal \& movement disorder & $48(0.1 \%)$ & $15(0.028 \%)$ & 0.001 \\
\hline G40-47 & Episodal \& paroxysmal disorders & $7408(16.01 \%)$ & $9373(17.58 \%)$ & 0.000 \\
\hline & Miscellaneous & $240(0.51 \%)$ & $118(0.22 \%)$ & - \\
\hline & Total & 46278 & 53315 & \\
\hline & *P-values calculations are based on z-test for two sample proportions. (At significance level of 0.05) \\
\hline
\end{tabular}




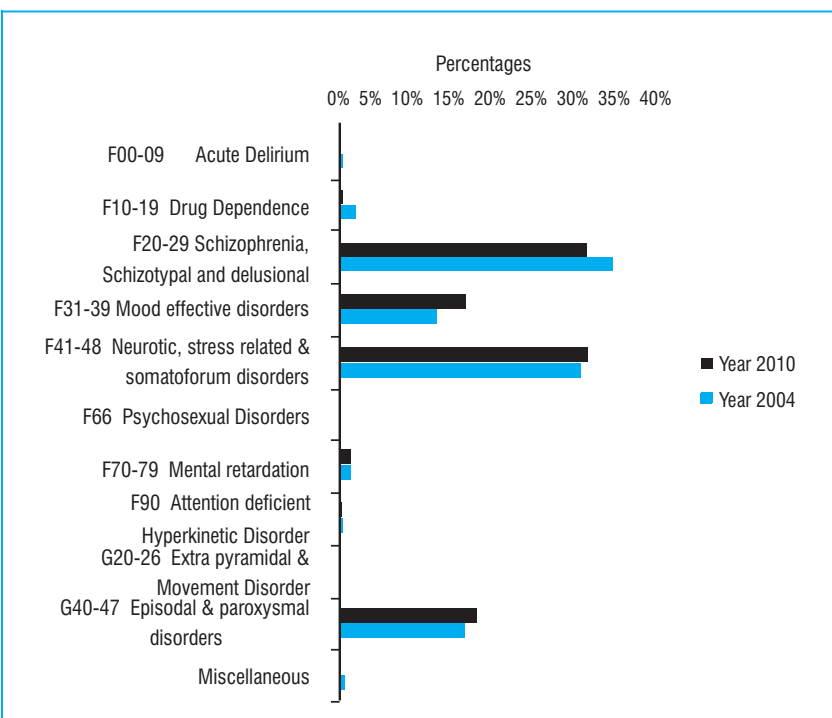

Fig-1. Comparison of disease pattern in 2004 \& 2010 acc-to ICD-10 classification

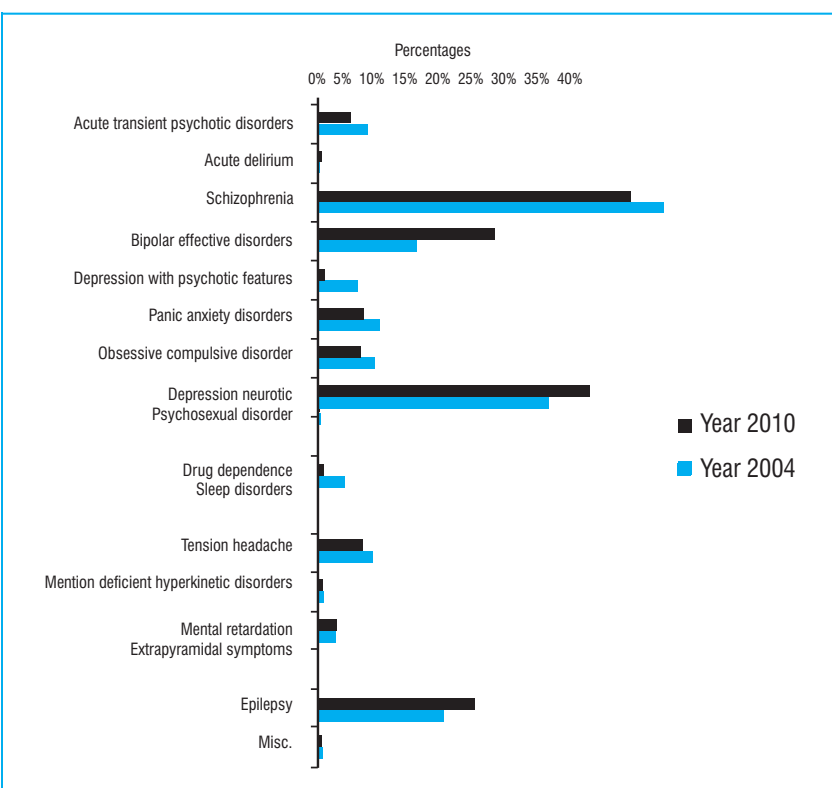

Fig-2. Comparison of disease pattern in 2004 \& 2010 acc-to ICD-9 classification

(depression), mood effective disorders and paroxysmal disorders. Many factors are involved like chronicity of schizophrenia, lack of consultation for depression and social stigma associated with consulting mental hospital services.
Mental illness not only constitutes $10.5 \%$ of the Global Burden of Disease (GBD), but also contributes $29 \%$ of the major causes of disability ${ }^{11}$. Among top five causes of disability five are mental. Mental retardation and drug addiction are not counted in it ${ }^{12,13}$.

When this pattern of diseases was compared with other studies in the country on institution based pattern of psychiatric morbidity it was found that most of the diseases were showing similar patterns, like schizophrenia and neurotic stress related disorders were predominant in the study followed by mood effective disorders and episodal \& paroxysmal disorders.

Based on results of surveys in other low-income countries it is estimated that the prevalence of schizophrenia is between 0.14 to $0.46 \%$ and epilepsy around $1 \%{ }^{14,15}$. These studies were community based so the figures were quite diluted as compared to our study, which was institution based.

In patients treated by an NGO in Pakistan, PAMH has reported that up to 44 percent of people, the majority women, were clinically depressed. Untreated depression is also a major cause leading to suicide. Suicide rate is also alarmingly increasing in Pakistan as reported by the Human Rights Commission of Pakistan $^{16}$.

Another study conducted in 2002 in Pakistan states psychosomatic disorders to be $5-7 \%$ prevalent in Pakistan, Seizure disorder $1 \%$ in urban and $2 \%$ in rural setting, Substance use disorder: $7 \%$ in urban and $6.5 \%$ in rural, obsessive-compulsive disorder: $2 \%$ in urban and $1 \%$ in rural setting. 3 while our hospital based data suggested that treatment seeking behavior are quite different from community picture as percentage of chronic mentally ill patients coming to mental hospital were higher .

According to National Survey (2000) in Pakistan, 
there are 5.1 million drug abusers and $51 \%$ of them are dependent on opiates like Heroin ${ }^{17}$. National assessment of opioid users in 2006 estimate 0.63 million users of opiates, out of them $77 \%$ (0.48 million) are estimated to use heroi $\mathrm{i}^{18}$. Overall prevalence rate in general population of Pakistan is $0.7 \%$. Cannabis, sedatives and tranquilizers, heroin, opium and other opiates were used. It was also estimated that number of addicts has not risen significantly since 2000 . In another study in nearby country Afghanistan, Substance related disorders, in particular addiction to opium, was common in the poppy growing areas in the south and east of the country ${ }^{19}$. Our study was not able to significantly look into this problem due to different study design.

As compared to providing treatment at mental hospitals, intervention at community level has shown increase detection and treatment of mental illnesse ${ }^{20,21}$. If such interventions are incorporated at primary health care level they are cost effective too.

\section{Limitations of study}

The study was hospital based, so findings can not be applied on general population. However, it provides useful information of mental disease pattern especially in Distt. Peshawar and generally in the province.

\section{CONCLUSIONS}

Hospital data is showing the overall picture of burden of disease.There is a need of culturally informed studies, which can inform us of base line data, epidemiology and people's help seeking behaviour?. There should be further need based studies with priority settings and planning for mental health problems.

\section{Copyright@ 04 Dec, 2012.}

\section{REFERENCES}

1. The Mental Health Context. Geneva, World Health Organization, 2003 (Mental. Health Policy and Service Guidance Package) www.who.int/entity/ mental_health/policy/.../3_context_WEB_07.pdf
2. George Pickett \& John J. Hanlon (1990). Public Health Administration and Practice. Ninth. Edition, p. 495. Times Mirror/Mosby College Publishing.

3. Amin A. Gadit, Najeeb Khalid, State of mental health in Pakistan: Service, education and Research. $1^{\text {st }}$ Edition, Corporate Printers Karachi, July 2002:36-37.

4. National Mental Health Ordinance $\mathbf{2 0 0 1}$ for Pakistan. Available at: www.emro.who.int/mnh/whd/PakistanOrdinance.pdf [cited; Nov 30, 2011]

5. Gadit AAM. Is There a Visible Mental Health Policy in Pakistan? J Pak Med Assoc 2007; 57:212-3.

6. Muhammad Irfan, Implementation of Mental Health Policy in Pakistan: a dream in search of reality? Editorial. JPMI 2010: vol24 (2)83-84.

7. International Classification of Diseases (ICD-10). Geneva, World Health Organization, 2011 [updated 2011; cited 2011, Dec 17] SEARO, WHO [about 2 screens]. Available at: http://apps.who.int/ classifications/apps/icd/icd10online.

8. Mental health. Geneva, World Health Organization, 2011. [Updated; 2011, cited; Dec 17, 2011] available at: http://www.who.int/mental_health/management/ depression/definition/en.

9. Mental health. Geneva, World Health Organization, 2011. [Updated; 2011, cited; Dec 17, 2011] available at: http://www.who.int/mental health/management/ schizophrenia/en/

10. Amin A. Muhammad Gadit, Mental Health Model: Comparison between a Developed and a Developing Country. Journal of medicine: Volume 1, Issue 1, 2007.

11. Fact Sheet $N^{\circ} 220$, Sep 2010. Mental Health: Strengthening our Response. Media centre. Geneva, World Health Organization, 2010. [updated 2011, cited; Dec 18, 2011] http://www.who.int/mediacentre /factsheets/fs220/en.

12. Investing in Mental Health, 2003. Geneva, World Health Organization, 2006. ISBN 924156257 Available at: www.who.int/mental_health/en/investing_in_mnh_fin al.pdf.

13. Muhammad Iqbal Afridi. Mental health: Priorities in 
Pakistan. JPMA Vol. 58, №. 5, May 2008.

14. Gater R. Mental health and Service Development in Pakistan. In: Mubbashar MH, Humayun A, eds. Mental health in the new millennium (volume 2). Rawalpindi, Institute of Psychiatry, 2001:356-68.

15. De Jong JTVM, Komproe IH, Van Ommeren M, El Masri M, Araya M, Khaled N, Van de Put W, Somasundaram D. Lifetime events and posttraumatic stress disorder in 4 post conflict settings. JAMA 2001; 286:555-62.

16. Humanitarian News and Analysis. PAKISTAN: Millions lack access to mental healthcare. [ updated May31, 2011; cited; Dec 18, 2011]. http://www.irin news.org/Report.aspx?Reportld=75204.

17. Drug Narcotic Control Division Govt. of Pakistan, U.N. Drug Control Program. Master plan for drug abuse control in Pakistan 1995-2000.
18. Drug Abuse Control Master Plan 2010-14 (Annex-II) Govt. of Pakistan, Ministry of Narcotics Control/Anti Narcotics Force, February 2010. Available at; www.anf.gov.pk/content/Drug\%20Abuse\%20Control\% 20Master\%20Plan\%202010-14.pdf.

19. De Jong E. Mental Health Assessment: Ghurian and Zendah Jan districts, Herat Province Afghanistan. Amsterdam/Kabul, Medecins sans Frontieres Holland, 1999.

20. Peter Ventevogel \& Frank Kortmann. Developing basic mental health modules for health care workers in Afghanistan Intervention 2004, Vol 2 (1):43-54.

21. Peter Ventevogel. The Psychiatric Epidemiological Studies in Afghanistan: A critical review of literature and future directions; Review Article. Jour. of Pakistan Psychiatric Society, Jan-June, 2005, Vol 2(1): 9 http://www.jpps.com.pk/display_articles.asp $? \mathrm{~d}=79 \& \mathrm{p}=$ art.

\section{AUTHOR(S):}

1. DR. RAHEELAH AMIN

FCPS (Community Medicine)

Assistant Professor

Department of Community Medicine,

Khyber Girl's Medical College, Peshawar

2. DR. RUBINA GUL

Assistt. Professor, Community Medicine Deptt.

Khyber Medical College, Peshawar.

3. DR. M. AKBAR KHAN

Lecturer, Community Medicine Deptt.

Khyber Girl's Medical College, Peshawar.

4. Dr. M. Tariq

Senior Specialist,

Govt. Sarhad Hospital for Psychiatric illnesses, Peshawar.
5. Dr. Shaffiullah

Lecturer, Community Medicine Deptt. Khyber Girl's Medical College, Peshawar

6. Dr. Amina Mehrab 4rth year MBBS Student, Khyber Medical College, Peshawar.

\section{Correspondence Address:}

\section{Dr. Raheelah Amin}

House No. 25, Street No. 2, Sector E-1,

Phase 1, Hayat Abad, Peshawar.

raheelahamin@yahoo.com

Article received on: 10/09/2012

Accepted for Publication: 04/12/2012 Received after proof reading: 10/12/2012

\section{PREVIOUS RELATED STUDIES}

Imtiaz Ahmad Dogar, Miss. Iram Hina, Miss. Memoona Kiran, Miss. Quratul Ain Arshed, Miss. Raisa Nazir. Etiological gender differences in psychiatric disorders (Original) Prof Med Jour 13(4)697-704 Oct, Nov, Dec, 2006. 